\title{
An enantioselective synthesis of isoquinuclidines from 3-substituted chiral pyridinium salts
}

\author{
Daniela Cristina dos Santos, ${ }^{\mathrm{a}}$ Rossimiriam P. de Freitas Gil, ${ }^{\mathrm{a}, *}$ Laurent Gil ${ }^{\mathrm{b}, *}$ and \\ Christian Marazano ${ }^{\mathrm{c}}$ \\ aDepartamento de Química, ICEx, UFMG, Av. Antônio Carlos 6627, Belo Horizonte, MG, Brazil \\ b Departamento de Química, ICEB, UFOP, Campus Morro do Cruzeiro, Ouro Preto, MG, Brazil \\ ${ }^{\mathrm{c}}$ Institut de Chimie des Substances Naturelles, CNRS, 91198 Gif-sur-Yvette, France
}

Received 25 June 2001; revised 2 July 2001; accepted 4 July 2001

\begin{abstract}
A new enantioselective approach to chiral isoquinuclidines, such as $\mathbf{1 5}, \mathbf{1 8}$ and $\mathbf{2 1}$, is reported. The key step of these syntheses is a cycloaddition between chiral dihydropyridines $\mathbf{1 4}$ or $\mathbf{2 0}$, now readily available from tetrahydropyridinium salts $\mathbf{6}$ or 11, and achiral dienophiles. The reaction proceeds with a very good endo-selectivity and moderate d.e. C 2001 Published by Elsevier Science Ltd.
\end{abstract}

Isoquinuclidine derivatives, such as $\mathbf{1}$ and related compounds, are valuable intermediates in alkaloid synthesis, especially Iboga-type indole alkaloids of which (+)-catharantine $\mathbf{2}$ is of special interest because of its role as biogenetic and synthetic precursors of vinblastine and related antitumoral bisindole alkaloids. ${ }^{1}$ Despite the progress in the synthesis of those alkaloids, no total asymmetric synthesis was reported hitherto, ${ }^{2}$ and few methods for the asymmetric synthesis of functionalized isoquinuclidines have been reported. ${ }^{3}$ This paper presents a convenient enantioselective access to derivatives 1.

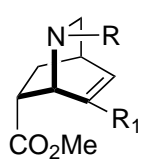

1

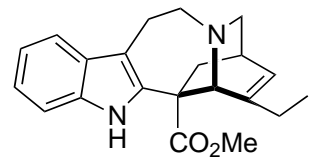

$(+)-2$
This approach takes advantage of the recently reported ${ }^{4}$ synthesis of tetrahydropyridines 3 (Scheme 1) from the corresponding pyridinium salts $\mathbf{4}$, and the observation that these intermediates are excellent precursors of 3-alkyl 1,6-dihydropyridines $\mathbf{5}$ which are difficult to obtain with good regioselectivity. ${ }^{3}$ These dihydropyridines were too unstable to be isolated, but could be trapped with common dienophiles, affording

\footnotetext{
* Corresponding authors. Tel.: +55 (031) 34995721 (R.P. de F.G.); fax: +55 (031) 35511707 (L.G.); e-mail: rossi@dedalus.lcc.ufmg.br; laurent@iceb.ufop.br
}

isoquinuclidine derivatives $\mathbf{1}$ via a cycloaddition reaction. With (+)-catharantine $\mathbf{2}$ as a synthetic target in mind, we therefore sought to explore conditions which should lead to enantiomerically pure isoquinuclidines by way of such cycloadditions. Using different chiral $N$-substituents ( $\mathrm{R}=$ chiral groups), our intention was to induce a $\pi$-facial stereoselectivity during the reaction between the in situ formed chiral dihydropyridine $\mathbf{5}$ and the achiral dienophile. We now report the preparation of these reactive intermediates from chiral pyridinium salts $\mathbf{4}$ and their reaction with dienophiles like methylacrylate to furnish chiral isoquinuclidine system $\mathbf{1}$, in few steps.

The chiral pyridinium salt 6 (Scheme 2), obtained from the corresponding Zincke salt, ${ }^{5}$ was reduced by treatment with $\mathrm{NaBH}_{4}$ in a mixture of methanol/water (90:10) to provide the tetrahydropyridine 7 in $70 \%$ yield. Oxidation with $m$-CPBA furnished diastereomeric $N$-oxides 8 which were filtered over alumina and treated immediately with trifluoroacetic anhy-

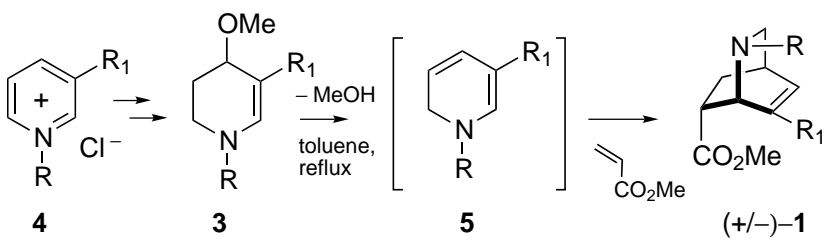

Scheme 1. 

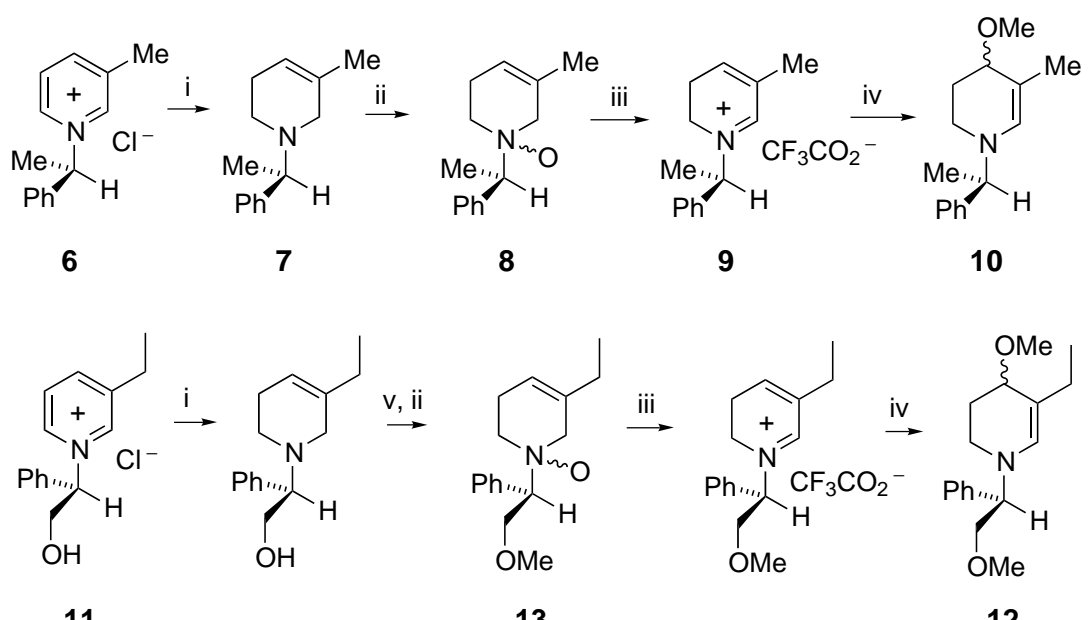

Scheme 2. Reagents: (i) $\mathrm{NaBH}_{4}$; (ii) $m$-CPBA, $\mathrm{CH}_{2} \mathrm{Cl}_{2}$; (iii) $\left(\mathrm{CF}_{3} \mathrm{CO}\right)_{2} \mathrm{O}, \mathrm{CH}_{2} \mathrm{Cl}_{2}$; (iv) $\mathrm{MeONa}, \mathrm{MeOH}$; (v) $\mathrm{NaH}$, MeI.

dride to afford quantitatively the 5,6-dihydropydinium salt 9, using conditions of the Polonovski-Potier reaction. ${ }^{6}$ The reaction of salt 9 with sodium methoxide in methanol gave the tetrahydropyridine $\mathbf{1 0}$ as a diastereomeric mixture and with a good yield $(78 \%$, $55 \%$ overall from 6). The same sequence, applied to salt 11, gave the corresponding diastereomeric tetrahydropyridines 12 in $45-50 \%$ overall yield. In that case the protection of the primary alcohol function as a methyl ether was done in order to prevent the reactivity of the hydroxyl group during the next steps. Care must also be taken due to the instability of $N$-oxides $\mathbf{1 3}$ which are sensitive to Cope elimination and, thus, must be used without further purification.

Heating of tetrahydropyridine $\mathbf{1 0}$ (Scheme 3) with methylacrylate (10 equiv.) in refluxing toluene overnight produced, via unstable dihydropyridine $\mathbf{1 4}$, the chiral diastereomeric isoquinuclidines $\mathbf{1 5}^{\mathbf{7}}$ and $\mathbf{1 6}$ in $55 \%$ yield. These diastereomers, as for other chiral isoquinuclidine derivatives (vide infra), were easily separated by flash chromatography and recovered in 35 and $20 \%$ yield, respectively. A small amount of the exo-adduct 17 was also detected.
The ratio 15:16:17 was found by GC to be 58:35:7, respectively, thus showing a modest d.e. for $15(26 \%)$, but an excellent endo-selectivity. Reaction of tetrahydropyridine 10 with $N$-phenylmaleimide (1.1 equiv.) in refluxing toluene for $2 \mathrm{~h}$ gave the adducts $\mathbf{1 8}^{8}$ and $\mathbf{1 9}$ in $77 \%$ isolated yield and a 60:40 ratio, respectively ( $20 \%$ d.e.). No exo-adduct was detected in this case.

Finally, heating of tetrahydropyridine $\mathbf{1 2}$ in refluxing toluene with methylacrylate in the conditions used for 10, gave adducts $\mathbf{2 1}$ and $\mathbf{2 2}$ in $60 \%$ yield and a $65: 35$ ratio, respectively (Scheme 4). Only traces of the exoadduct were detected.

The configurations of all isoquinuclidines were unambiguously established by comparison with analogous derivatives. ${ }^{3 \mathrm{~b}}$ Despite the low facial selectivity observed (d.e. $=20-30 \%$ ), this methodology is very practical to produce functionalized optically active isoquinuclidines with very good endo-selectivity and good yields. In particular the present method considerably shortens the previously reported approach ${ }^{3 \mathrm{~b}}$ which makes use of a tedious multistep synthesis of 3-alkyl 5,6-dihydropyridines.

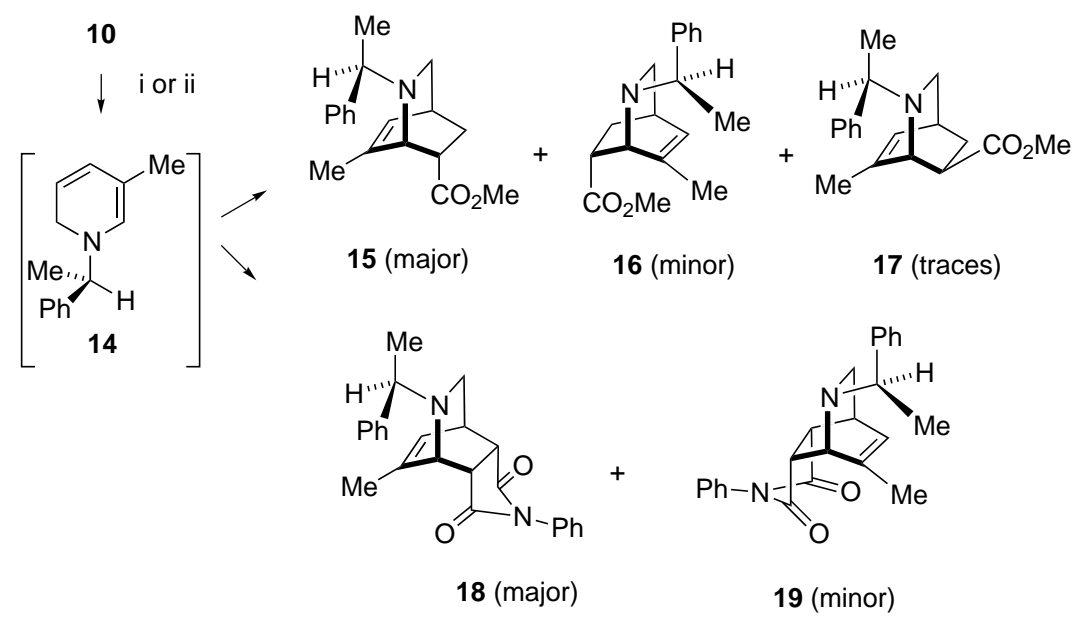

Scheme 3. Reagents and conditions: (i) Methylacrylate, toluene, reflux, overnight; (ii) $N$-phenylmaleimide, toluene, reflux, 2 h. 


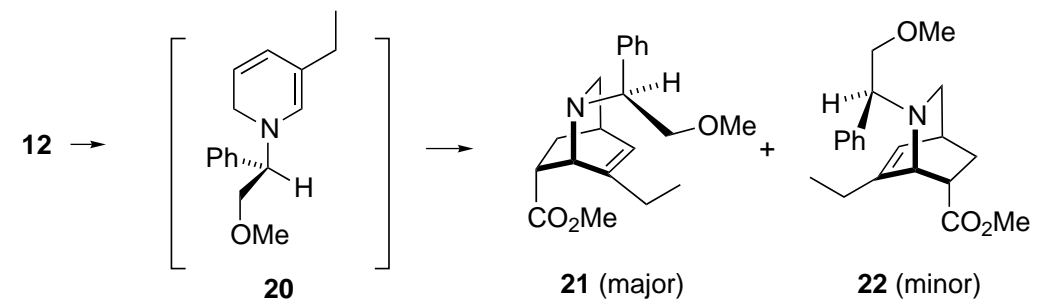

Scheme 4.

\section{Acknowledgements}

Financial support from FAPEMIG-MG Brazil and fellowship for D.C.S. from CNPq Brazil are gratefully acknowledged.

\section{References}

1. (a) Mangeney, P.; Andriamialisoa, R. Z.; Langlois, N.; Langlois, Y.; Potier, P. J. Am. Chem. Soc. 1979, 101, 2243 and references cited therein; (b) Potier, P. Pure Appl. Chem. 1986, 58, 737.

2. (a) Szántay, C.; Bólcskei, H.; Gács-Baitz, E. Tetrahedron 1990, 46, 1711; (b) Reding, M. T.; Fukuyama, T. Org. Lett. 1999, 1, 973 and references cited therein.

3. (a) Trost, B. M.; Romero, A. G. J. Org. Chem. 1986, 51, 2332; (b) Mehmandoust, M.; Marazano, C.; Singh, R.; Gillet, B.; Césario, M.; Fourrey, J.-L.; Das, B. C. Tetrahedron Lett. 1988, 29, 4423; (c) Marazano, C.; Yannic, S.; Génisson, Y.; Mehmandoust, M.; Das, B. C. Tetrahedron Lett. 1990, 31, 1995.

4. Gil, L.; Gateau-Olesker, A.; Marazano, C.; Das, B. C. Tetrahedron Lett. 1995, 36, 707.

5. Génisson, Y.; Marazano, C.; Mehmandoust, M.; Gnecco, D.; Das, B. C. Synlett 1992, 431.

6. Grierson, D. S.; Harris, M.; Husson, H. P. J. Am. Chem.
Soc. 1980, 102, 1064.

7. The structure was established by comparison with an authentic sample, see Ref. 3b. Selected data for 15: $[\alpha]_{\mathrm{D}}=$ +10 (c 0.5, $\left.\mathrm{CHCl}_{3}\right)$; IR $\left(\mathrm{cm}^{-1}\right)$ 3031, 2968, 2950, 2875, $2850,1737,1656,1600,1494,1450,1431 ;{ }^{1} \mathrm{H}$ NMR $\left(\mathrm{CDCl}_{3}, 250 \mathrm{MHz}\right) \delta 1.23(3 \mathrm{H}, \mathrm{d}, J=6.4 \mathrm{~Hz}), 1.63(3 \mathrm{H}, \mathrm{d}$, $J=1.7 \mathrm{~Hz}), 1.60-1.85(2 \mathrm{H}, \mathrm{m}), 2.06(1 \mathrm{H}, \mathrm{dt}, J=9.3 \mathrm{~Hz}, 2.5$ $\mathrm{Hz}), 2.53(1 \mathrm{H}, \mathrm{m}), 2.98(1 \mathrm{H}, \mathrm{dd}, J=9.3 \mathrm{~Hz}, 2.5 \mathrm{~Hz}), 3.00$ $(1 \mathrm{H}, \mathrm{ddd}, J=9.6 \mathrm{~Hz}, 4.5 \mathrm{~Hz}, 3.2 \mathrm{~Hz}), 3.23(1 \mathrm{H}, \mathrm{q}, J=6.4$ $\mathrm{Hz}), 3.48$ (1H, dd, $J=3.2 \mathrm{~Hz}, 1.8 \mathrm{~Hz}), 3.52(3 \mathrm{H}, \mathrm{s}), 6.03$ $(1 \mathrm{H}, \mathrm{ddd}, J=6.7 \mathrm{~Hz}, 1.8 \mathrm{~Hz}, 1.7 \mathrm{~Hz}), 7.20-7.45(5 \mathrm{H}, \mathrm{m})$; ${ }^{13} \mathrm{C}$ NMR $\left(\mathrm{CDCl}_{3}, 62.89 \mathrm{MHz}\right) \delta 21.14,23.06,26.58$, 30.99 , 44.26, 51.40, 53.53, 55.67, 64.89, 126.90, 127.21, 128.54, 137.87, 146.18, 174.47; HRMS calcd for $\mathrm{C}_{18} \mathrm{H}_{23} \mathrm{NO}_{2}$ : 285.1729; found: 285.1725 .

8. Selected data for 18: $[\alpha]_{\mathrm{D}}=+16\left(c 1.62, \mathrm{CHCl}_{3}\right)$; IR $\left(\mathrm{cm}^{-1}\right)$ 3031, 2968, 2937, 1769, 1712, 1693, 1431, 1400, 1343, 1168; ${ }^{1} \mathrm{H}$ NMR $\left(\mathrm{CDCl}_{3}, 300 \mathrm{MHz}\right) \delta 1.22(3 \mathrm{H}, \mathrm{d}, J=6.4 \mathrm{~Hz})$, $1.34(3 \mathrm{H}, \mathrm{d}, J=1.5 \mathrm{~Hz}), 2.12(1 \mathrm{H}, \mathrm{dd}, J=9.6 \mathrm{~Hz}, 2.4 \mathrm{~Hz})$, $2.86(1 \mathrm{H}, \mathrm{dd}, J=7.8 \mathrm{~Hz}, 3 \mathrm{~Hz}), 3.05(1 \mathrm{H}, \mathrm{m}), 3.09(1 \mathrm{H}$, $\mathrm{dd}, J=9.6 \mathrm{~Hz}, 2 \mathrm{~Hz}), 3.18(1 \mathrm{H}, \mathrm{dd}, J=7.8 \mathrm{~Hz}, 4 \mathrm{~Hz}), 3.18$ $(1 \mathrm{H}, \mathrm{q}, J=6.4 \mathrm{~Hz}), 3.55(1 \mathrm{H}, \mathrm{dd}, J=4 \mathrm{~Hz}, 1.5 \mathrm{~Hz}), 4.44$ $(1 \mathrm{H}, \mathrm{d}, J=14 \mathrm{~Hz}), 4.52(1 \mathrm{H}, \mathrm{d}, J=14 \mathrm{~Hz}), 5.70(1 \mathrm{H}, \mathrm{m})$, $7.20-7.38(10 \mathrm{H}, \mathrm{m}) ;{ }^{13} \mathrm{C} \mathrm{NMR}\left(\mathrm{CDCl}_{3}, 75.47 \mathrm{MHz}\right) \delta$ 20.89, 22.93, 33.92, 41.47, 42.15, 45.96, 52.13, 54.90, 64.93, $123.48,127.14,127.37,127.73,128.39,128.61,128.82$, 135.90, 139.41, 145.20, 176.77, 178.62; HRMS calcd for $\mathrm{C}_{25} \mathrm{H}_{27} \mathrm{~N}_{2} \mathrm{O}_{2}$ : 387.2073; found: 387.2071. 